\title{
Inventários, espaço, memória e sensibilidades urbanas
}

\section{Inventories, space, memory and urban sensitivities}

\author{
Antonio Gilberto Ramos Nogueira ${ }^{1}$
}

\begin{abstract}
RESUMO
O artigo busca traçar algumas reflexões em torno da relação entre inventários e sensibilidades urbanas, tomando como base os desdobramentos do projeto "Patrimônio e História Local: Inventário de Referências Culturais do bairro Benfica (CE)", desenvolvido no âmbito do Grupo de Estudos e Pesquisas em Patrimônio e Memória (GEPPM)/ Universidade Federal do Ceará (UFC)/ Conselho Nacional de Desenvolvimento Científico e Tecnológico (CNPq). Ao identificar e documentar práticas, usos, apropriações e sentidos atribuídos por distintos sujeitos que estão ligados direta ou indiretamente aos espaços do bairro Benfica, diferentes sensibilidades foram acionadas revelando a história, a memória e o patrimônio da cidade. A aplicabilidade do inventário levantou a necessidade de problematizar a experiência sensível da urbe marcas de outras temporalidades -, manifestada em sua materialidade e subjetividade. Nesta perspectiva, os inventários constituem-se como um exercício privilegiado de aprendizado no qual o dever da história e o lugar da memória, consubstanciados ao ensino da história, contribuem para desnaturalizar os usos do passado e o patrimônio da cidade. Com isso, o artigo aborda as potencialidades do inventário como recurso metodológico para a produção de conhecimento histórico e educação dos sentidos.
\end{abstract}

Palavras-chave: inventários; patrimônio cultural; memória; sensibilidades urbanas.

\footnotetext{
ABSTRACT

This article aims to outline some reflections about the relations between inventories and urban sensitivities, on the basis of developments of the

DOI: $10.1590 / 0104-4060.43471$

1 Universidade Federal do Ceará. Fortaleza, Ceará, Brasil. Departamento de História. Av. da Universidade, nº 2762, Benfica. CEP: 60020-180.E-mail: antonioantonio@uol.com.br
} 
project "Heritage and Local History: Inventory of Cultural References of the Benfica neighbourhood (CE)", developed on the scope of the Group of Studies and Research on Heritage and Memory - (GEPPM)/ Federal University of Ceará (UFC)/ National Council of Scientific and Technological Development $(\mathrm{CNPq})$. By identifying and documenting practices, uses, appropriations and senses attributed by different individuals linked direct or indirectly to the spaces of the Benfica neighbourhood, different sensitivities were triggered revealing the history, memory and heritage of the city. The applicability of the inventory put the need to problematize the sensible experiences of the city - traces of other temporalities -, expressed in its materiality and subjectivity. In this perspective, inventories are constituted as a privileged exercise of learning in which the duty of history and the place of memory, linked to the teaching of history, contribute to denaturalize the uses of the past and heritage of the city. Therefore, this paper deals with the potentials of inventories as a methodological resource used to produce historical knowledge and sensory education.

Keywords: inventories; cultural heritage; memory; urban sensitivities.

Na nova história do patrimônio no Brasil o desenvolvimento da noção de patrimônio cultural e inventário tem percursos simultâneos. A noção alargada de patrimônio cultural que marcou as duas últimas décadas veio conferir aos inventários um novo lugar nas políticas de preservação corrigindo, dessa forma, uma dada tradição preservacionista que consagrara o tombamento como sinônimo de preservação. O uso do inventário se limitava, muitas vezes, a reconhecer valores preestabelecidos ao invés de realizar um verdadeiro trabalho de investigação dos processos de valoração do patrimônio cultural. (NOGUEIRA, 2007, 2014). Essa nova configuração do campo do patrimônio na atualidade, ao mesmo tempo em que tem repertoriado um conjunto expressivo de novos patrimônios, tem igualmente contribuído para uma proliferação de inventários de diferentes modalidades.

Não é intento deste artigo se debruçar sobre a história e a evolução dos inventários, nem tão pouco estabelecer um balanço das diversas metodologias e procedimentos na constituição dos inventários que têm orientado as experiências preservacionistas no Brasil em suas escalas local, regional e nacional. O que se propõe é refletir sobre os usos e potencialidades dos inventários quando aplicado em situação urbana. Interessa problematizar os usos do inventário como um instrumento que possibilita ver a cidade e seu patrimônio. Entendendo que a experiência sensível da urbe passa por uma educação dos sentidos: é preciso saber ver a cidade em suas múltiplas temporalidades. Nesta perspectiva, os inventários constituem-se como um exercício privilegiado de aprendizado que acionam a história e a memória nas diferentes leituras sobre o passado da cidade. 
Este exercício de uma educação dos sentidos, que vislumbra nos inventários um recurso metodológico capaz de evocar as sensibilidades urbanas, foi construído a partir do projeto "Patrimônio e História Local: Inventário de Referências Culturais do bairro Benfica (CE)"', desenvolvido no âmbito do Grupo de Estudos e Pesquisas em Patrimônio e Memória (GEPPM), da Universidade Federal do Ceará (UFC), vinculado ao Diretório dos Grupos de Pesquisa do Conselho Nacional de Desenvolvimento Científico e Tecnológico (CNPq). Pautado na indissociabilidade da relação ensino, pesquisa e extensão, o projeto teve suas ações voltadas para o projeto político pedagógico do curso de História da UFC e seus temas transversais, sobretudo, aqueles relacionados à memória, patrimônio, identidade e cidadania. Ancorada no uso da história oral $^{3}$ a identificação contou ainda com escritos memorialísticos, fotografias, documentação cartorial, mapas e plantas da cidade.

Sem ater-se a uma reflexão circunscrita à experiência mesma da pesquisa, o artigo está assentado em questões que colocam em relevo as imbricações entre história e memória no campo do patrimônio e destaca o lugar da universidade (graduação em História) na produção do conhecimento sobre o patrimônio cultural da cidade por meio dos inventários.

\section{Patrimônio cultural, memória e sensibilidade urbanas}

Patrimônio e memória são indícios e sintomas das novas sensibilidades temporais contemporâneas, constatou François Hartog (2006). Enquanto um recurso para a crise do tempo, inscrevem-se num movimento que evidencia a onipresença do presente. Sinais do novo "regime de historicidade" que o historiador do tempo identificou como "presentismo" - expressão dos dilemas que se vive entre a amnésia e a vontade de nada esquecer. Nesse processo de

2 O Projeto foi contemplado pelo Edital Pró-Reitoria de Extensão-Universidade Federal do Ceará/ Edital PROEXT 2011, realizado em 2012 e 2013. Fizeram parte da equipe a prof ${ }^{a}$ Ana Carla Sabino Fernandes, o pesquisador Carlos Renato Freire, os alunos da graduação: Hanna Ávila de Paiva, Marliene Mariana de Meneses, Rayanna Moreira Nunes, Pedro Paulo da Silva Martins e Hildebrando Maciel Alves.

3 Para este artigo foram usadas seis entrevistas: três realizadas pelo PROEXT (Laurence Kroeff Bisol, entrevistador Hidelbrando Maciel Alves; Dona Erismar Ferreira e Seu Francisco Ferreira, entrevistador Pedro Paulo da Silva Martins) e duas realizadas pelo pesquisador Renato Mesquita Rodolfo (Dona Clarice Costa e Seu Francisco de Assis Martins). Sobre os usos e procedimentos na constituição de um acervo pautado em fontes orais a pesquisa se apoiou nos estudos de Verena Alberti (2005) e Alessandro Portelli (1997). 
mudanças significativas da relação que estabelecemos com o tempo, o desejo e a necessidade de passado emergem alimentando e moldando a nova concepção de patrimônio cultural, capaz de evocar formas diversas de lidar com a ordem do tempo. Em meio à angústia e sensação de mal-estar, causadas pelo encolhimento dos horizontes de tempo e espaço, patrimônio e memória cumprem a função de proteção e apaziguamento das identidades ameaçadas. (HARTOG, 2006; HYSSEN, 2000; NOGUEIRA, 2014).

A esse tempo saturado de presente, o fenômeno da patrimonialização se impõe como seu correspondente. Em resposta a uma demanda social voltada para o passado, o ato de patrimonializar passa então a designar todo o processo de atribuição de valor e significado a bens e práticas culturais que são identificados e reconhecidos segundo os interesses específicos dos grupos de identidade. Assim, a "lógica da conservação patrimonial" ou a "maquinaria patrimonial", para usar a expressão de Henri-Pierre Jeudy (2005), são forjadas para fundamentar o recurso identitário conferido ao patrimônio, manifestação da obsessão contemporânea de tudo preservar. (NORA, 1993).

Nessa lógica patrimonial regida pela seleção e valoração de tudo o que deve ser lembrado ou esquecido, seguindo as dinâmicas identitárias, como se dá o processo de recuperação do passado da cidade compreendida como espaço de produção do social cujas múltiplas temporalidades conferem sentidos a este espaço? Qual o papel da história e da memória no despertar de uma sensibilidade urbana com vistas a apreender os traços do passado da cidade? Como o recurso ao inventário possibilita tal empreendimento?

"O essencial é saber ver", diz o verso de Alberto Caeiro, um dos heterônimos de Fernando Pessoa. No poema "O que vemos das cousas" (PESSOA, 1914, p. 44-45), a pulsão criativa do poeta expressa formas possíveis de sentir e conhecer o mundo. Aqui, o verso se traduz num repertório interessante para problematizarmos o que nos ensinou Sandra Pesavento (2004) sobre a experiência sensível do mundo. Manifestação de uma subjetividade ou uma sensibilidade partilhada, cujos registros são passíveis de serem apreendidos pelo historiador.

Sensibilidades se exprimem em atos e em ritos, em palavras e imagens, em objetos da vida material, em materialidades do espaço construído. Falam, por sua vez, do real e do não-real, do sabido e do desconhecido, do intuído ou do inventado. Sensibilidades remetem ao mundo do imaginário, da cultura e seu conjunto de significações construído sobre o mundo. (PESAVENTO, 2004, p. 58). 
"O essencial é saber ver", mas, para isso, "é preciso um aprendizado de desaprender", diz o poeta.

Talvez seja este o mote de inspiração para adentrar os desafios colocados ao historiador do patrimônio e o das sensibilidades urbanas. Afinal, ambos têm a intencionalidade de recuperar a historicidade das sensibilidades e interpretá-las segundo os rastros que nos deixaram. História e memória intercambiam-se na construção de narrativas desse tempo transcorrido.

Se o patrimônio cultural é aquilo que define o outro a partir de referenciais identitários e é referendado por valores atribuídos a bens e práticas culturais em diferentes momentos e espaços, é preciso atentar para a historicidade desse processo. (NOGUEIRA, 2014). A chave está na questão do "olhar" e da perspectiva de abordagem do bem cultural. (FONSECA, 2008). Como os inventários possibilitam ver com os olhos da história aquilo que toca a memória no despertar das sensibilidades?

A lida com "[...] as sensibilidades de um outro tempo e de um outro no tempo, fazendo o passado submergir no presente" (PESAVENTO, 2004) é o desafio de quem deseja ler a cidade e seu patrimônio. Na perspectiva sugerida por Michel de Certeau (1994), é preciso saber ler a cidade como uma escrita do espaço, da mesma forma que refletir sobre o patrimônio cultural é percebê-lo como uma modalidade de escrita do passado, conforme considerou Manoel Luiz Salgado Guimarães (2011).

A escrita da cidade é feita de desenhos, mapas, ruas, praças, monumentos, imagens. Escrita que carrega, em sua singularidade, a marca do visual. Enquanto construto inventado e fabricado pelo homem para contar sua história, a cidade, como forma e imagem, se sobressai. Separando e unindo, o artefato, essa coisa feita, construída, gera espaço e forma. Nesse processo, em que o universo material é socialmente apropriado por diferentes sujeitos, múltiplos sentidos constroem lugares, territorialidades e imagens da cidade. (MENEZES, 1985). A cidade é, então, imagem. Imagem e espaço que se dão a ver e se dão a ler. Daí a importância de saber ver a cidade como um espaço de aprendizagem.

Mas, se estamos entendendo a cidade como escrita do espaço, as sensibilidades urbanas remetem aos afetos que se exprimem a partir das relações sociais que os moradores estabelecem com a cidade. São essas relações e atribuição de sentidos que significam o lugar - uma "configuração instantânea de posições" - que, para Certeau (1994, p. 201), implica uma "indicação de estabilidade". São elas que acabam por definir e delinear os contornos e paisagens urbanas, criando referenciais culturais que nos ajudam a apreender as imagens da cidade.

Ao empreendermos o esforço de leitura dessas imagens e referenciais, "[...] estamos conscientes de que eles estão impregnados de memória e de significações que se constroem e se modificam pelas experiências e vivências 
sociais posteriores, exprimindo diferentes temporalidades". (FENELON, 1999, p. 289). Dessa forma, a cidade constitui-se, igualmente, em escritas da memória sobre o espaço.

Nome de ruas, praças, prédios, monumentos são dispositivos mnemônicos que nos ajudam a localizar os múltiplos e conflituosos tempos que a cidade contém. É nas reminiscências individuais ou coletivas que a materialidade do espaço e também a instância do sensível e do simbólico emergem como forma de garantir permanência e estabilidade às identidades ameaçadas diante do espaço transformado. (BENJAMIN, 1993; HALBWACHS, 1990; BRESCIANI, 2014). Tal processo, muitas vezes traumático, oblitera a sensibilidade e a possibilidade de ver a cidade, exigindo assim uma ação deliberada de "[...] uma vontade e mesmo de um aprendizado, que só podem ser despertados pela ativação de um olhar sensível e por um processo que implica ensinar a pensar". (PESAVENTO, 2005, p. 12).

\section{Benfica: memória, história, lugar}

[...] o Benfica tem um pouco de boemia, um pouco residencial, um pouco da questão da academia. É, tem muitas famílias ainda que moram. Mas, o meu bairro é um bairro muito do ponto de vista muito isolado, as pessoas não estão na rua, né; que é o contrário do Benfica. No lugar que eu moro as pessoas estão atrás dos seus muros grandes né, altos né, diferentes. As ruas muitas vezes vazias. O Benfica é o contrário, né. Você tem essa efervescência do dia-a-dia. Do comércio, das escolas, dos bares, né, das casas. As pessoas muito ainda sentam nas calçadas, no meu bairro já é um pouco diferente. (Entrevista realizada em 19/09/2012).

Interessante como o fragmento acima traduz, em alguma medida, as temporalidades subjetivas que conformam o espaço do Benfica. No presente da enunciação, condição mesma da rememoração (SARLO, 2007, p. 49), o relato de Laurence (secretário geral do Partido Pátria Livre - PPL) instiga a pensar como práticas e representações constroem, sob camadas do tempo, um espaço delineado por fronteiras e territórios interpenetrados. É o referente de contraposição que opera as percepções sobre o tempo físico e social, incidindo nas práticas sociais, e, ao mesmo tempo, molda as formas do espaço da cidade de Fortaleza. 
Vocacionado a ser um lugar de residir e "bem ficar", em suas origens (final do século XIX), o Benfica nunca deixou de ser um lugar de fluxos contínuos (de pessoas, comércio e serviços) dada a sua localização de proximidade com o centro, caminho para o "sertão" e final de linha de bonde e ônibus respectivamente. Do lugar em que as pessoas estão isoladas "atrás dos seus muros grandes", o Benfica é seu contrário: as pessoas estão nas ruas, nos comércios, nos bares, nas escolas, "muitos ainda sentam nas calçadas". É uma singularidade do bairro do Benfica que o individualiza em sua interface com a cidade e o coloca numa condição de vetor de uma identidade urbana. É um patrimônio compartilhado por todos que têm, na experiência sensível da urbe, itinerários atravessados/ selecionados pelo Benfica.

Ao colocar em perspectiva uma cartografia dos sentidos construída a partir de uma memória do bairro e de uma memória no bairro, a narrativa construída por Laurence aproxima-se da concepção aventada por Certeau (1994, p. 200) de que os espaços são lugares praticados. São, ainda, relatos da experiência do vivido e dos sentidos atribuídos aos espaços, constituindo-se em referenciais culturais e memórias.

Tal perspectiva ganha potencialidade quando comparada com o relato de Dona Clarice Costa, oitenta anos, moradora do Benfica, que diz:

Eu achava o Benfica muito bom de se morar, não tinha ladrão, só em não ter ladrão era uma beleza, você podia passar até meia noite aí na calçada e não aparecia ninguém, hoje em dia você não pode nem abrir a sua porta. Eu não me sento na calçada, mas não sento mesmo. (Entrevista realizada em 14/01/2015).

Nota-se que o "sentar na calçada" reveste-se de um sentido topofílico na construção de uma memória afetiva do e sobre o bairro Benfica. Na condição de um elo afetivo entre a pessoa e o lugar ou ambiente físico, como definiu o geógrafo Yi Fu Tuan Fuan (2012), corresponde ao signo de uma visualidade que orienta e fundamenta as representações e os referenciais sobre o passado e o presente evocados a partir das percepções do espaço experienciado. A violência como marca de uma sensibilidade urbana do presente se faz visível como realidade objetivada nos dois relatos. Na dinâmica entre estes dois olhares, o "sentar na calçada" é o elo de acesso às camadas sobrepostas de memória (individual e coletiva...) que nos possibilita entrever o traçado de cartografias em seu processo de criação. 
Ao longo do inventário, as entrevistas foram revelando uma escrita sobre o espaço, marcada pela subjetividade de moradores e de pessoas que expressam uma vida latente no Benfica. São diversos atores sociais que, por um motivo ou por outro, vivem uma boa parte do seu dia no Benfica e seus arredores e, consequentemente, estabelecem laços dos mais diversos sentidos para com o espaço vivenciado e para com as pessoas que o compõem.

As memórias do aposentado Sr. Francisco de Assis Martins (Seu Francisco), morador nascido no Benfica, trazem indícios importantes dos traços do passado do bairro e da cidade:

Aqui as casas, inclusive, tinham aquela coisa como é aqui esse das irmãs, esse dispensário, era aquela casa tipo, estilo, que tem bem um negócio bem sul-americano mesmo, parece aquelas casa da Espanha, na frente você vê um casarão, mas dentro, normalmente, tinha um pátio, com árvores, com jardins, sempre eram assim as casas, por causa do clima né, em Fortaleza, nessa época, era um clima muito mais salubre do que hoje né, o pessoal vinha se tratar, os grandes empreendimentos foi que acabaram mais, né, e o asfalto também, né.

Porque, aqui, não! Se você vê, aqui, no Benfica, era uma beleza pro clima. Até essas voltas, isso aqui era a coisa mais aprazivel. Eu era menino, me lembro demais; e essa lagoa que aterraram, aqui, a lagoa do Tauape, começava aqui e ali atrás e ia até na... Aí aterraram fizeram a Cobal, né. Ai, quando eles fizeram o canal, esse canal que trás água, ai pronto. Aterraram a lagoa e fizeram... Hoje está tudo construido, né, você... onde tem aquela caixa d'água enorme... Ali era dentro da lagoa mesmo, a lagoa grande, bonito aqui, refrescava esse clima do Benfica todinho, essas casas com as mangueiras nos quintais, com as coisas, né? Essa era uma Fortaleza europeia, que, aos poucos, estão acabando, né. (Entrevista realizada em 22/08/2012).

O relato de Seu Francisco figura como um testemunho sensível de sua relação de pertencimento com o espaço do Benfica. Na condição de "nativo", suas percepções acerca das mudanças ocorridas no bairro apontam para as diferentes práticas sociais e apropriações que se desdobraram em novos usos e funções dados ao espaço. O sentido de "lugar" que encerra o relato de Seu Francisco faz do Benfica um "espaço da recordação", conforme sugere a acepção de Aleida Assman (2011). Natureza e cultura são aqui geradoras de sensibilidades determinadas pelo espaço recordado. São igualmente marcas de historicidade que a memória do Seu Francisco contém: “[...] nessa época era um clima muito 
mais salubre do que é hoje, né, o pessoal vinha se tratar... aqui era a coisa mais aprazivel, eu era menino e me lembro demais e essa lagoa que aterraram aqui, a lagoa do Tauape [...]".

O clima salubre e aprazível do Benfica é fruto de um programa de necessidades que engendrou um estilo próprio de casas com seus pátios cheios de árvores e jardins. No relato de Seu Francisco, os olhos do menino nos levam a uma viagem em que é possível vislumbrar as brincadeiras de infância entre os aromas e as sombras dos manguezais e banhos na lagoa do Tauape. São itinerários e percursos do espaço praticado de uma paisagem do Benfica que, aos olhos do adulto, ficaram no passado. Uma outra paisagem e outros referenciais foram sendo construídos, soterrando antigos marcos naturais.

Em outro fragmento da entrevista de Dona Clarisse, o despertar de uma sensibilidade urbana sobre as temporalidades da cidade coaduna-se com as memórias de Seu Francisco.

Quando eu vim morar aqui, chamavam de Gentilândia. Esse nome era da família Gentil. Eu ainda conheci uns. Essa parte aqui até o [Estádio] Presidente Vargas, isso aqui tudo era dos Gentil; até a Reitoria, por acolá... que a Reitoria era do Antônio Gentil, era da família Gentil. Quando eu cheguei aqui, a Universidade só tinha aquela casa [a Reitoria], mas ainda era muito diferente, isso aqui era muito diferente. Era uma casa grande, comum que era dos Gentil, mas não morava mais ninguém, já estava começando a ser Universidade ali. Depois, foi que reformaram, foi reformando, reformando e foi que cresceu, mas não era grande daquele jeito não. Aos poucos ela foi aumentando, crescendo, crescendo. Aqui era muito diferente. Hoje em dia, eu digo que é Benfica brega. Hoje é diferente, aqui antigamente era conhecido como uns dos lugares chique, um lugar que só morava gente mais ou menos, hoje em dia mora qualquer.. um pedinte chega e arranja um negocinho ali numa pessoa e mora, pode ser ladrão, pode ser maconheiro, pode ser qualquer coisa. Uma casa do José Gomes, ele tinha uma mercearia, era considerado rico naquela época, então José Gomes morreu e venderam a casa, dessa casa hoje ai tem uns 15 ou 20 "moquifos", uns quartinhos que ali é cheio de gente. Eu nunca fui por ali porque eu não gosto. Todo fim de semana. Tem um forró aí, dia de sábado e domingo, é o dia todo tocando, só quem merece mesmo morar aqui. Eu sei é que aqui mudou muito, mudou muito, muito. É tanto que eu digo que, hoje, o Benfica já foi Benfica, que até tinham uns engenheiros ali que diziam que o melhor bairro era o Benfica. Aqui era o lugar chique de se morar, era muito diferente. (Entrevista realizada em 14/01/2015). 
A fala de Dona Clarice traz novos elementos da complexa relação espaço e memória cujos efeitos colocam em tensão uma memória fundadora do bairro: o "Benfica Chique", associada à família Gentil e à chegada da UFC; e uma imagem do presente: "Benfica Brega" que, dadas às transformações ocorridas no bairro, reverbera-se em estranhamento e não reconhecimento. A presença da família Gentil no bairro, cujo palacete foi adquirido para abrigar a sede da Reitoria, é a evidência clara de que o Benfica foi lugar de distinção escolhido pela elite local para residir em suas chácaras entre o final do século XIX e início do XX.

Além das casas do clã dos Gentis, o empresário José Gentil, dono da firma "Frota \& Gentil", que ainda abrigava um banco e uma imobiliária, foi responsável pela construção de vilas com moradias mais modestas. Tal empreendimento contribuiu para a constituição de um referencial identitário de fronteiras materiais e simbólicas que posteriormente se desdobraram na origem da Gentilândia, um bairro dentro do bairro (não oficial), e na criação do Gentilândia Atlético Clube. Diversos esforços e empreendimentos se converteram na consolidação dessa memória. (CANDOU, 2011). Nome de ruas, praças, memorial (Confraria da Gentilândia) e a aprovação da Lei no 8.480 (de 24/07/2000), que oficializa a Gentilândia como um bairro, parecem simbolizar a força que a memória dos lugares guarda em si.

Segundo os estudos de Aleida Assman (2011), a expressão "memória dos lugares" carrega em sua formulação a possibilidade de identificar tanto uma "memória que se recorda dos locais", quanto sugere uma "memória que está por si só situada nos lugares". (ASSMAN, 2011, p. 317). Na proposição de Assman, os relatos acima se encaixam nas duas perspectivas de formulação que nos ajudam a pensar a "memória dos lugares". As expressões "eu era menino e me lembro" ou "quando eu vim morar aqui" são testemunhos que assumem uma condição de memória que recordam o espaço investindo-se, assim, de autoridade para contar e narrar o acontecimento. De outro lado, também estes lugares parecem portadores de uma memória em si que transcende essas vivências individuais e se inscreve no imaginário do Benfica.

A chegada da Universidade ao bairro fundou o terceiro tempo do Benfica - marca de um novo momento de ocupação e deslocamentos ditados pela experiência de modernização pela qual a cidade de Fortaleza passava. (NOGUEIRA, 2012). A instalação do edifício-sede da Reitoria no Benfica, em 1956, e a posterior construção de novos edifícios e equipamentos universitários representaram um divisor de águas na nova configuração do espaço físico e natural do bairro. Um outro referencial estético se instaura no espaço e tempo do Benfica, com a inscrição da arquitetura moderna a partir da construção da Concha Acústica e demais edifícios (Centro de Humanidades), conforme estabeleceu o Inventário de Arquitetura Moderna Cearense. (JUCÁ et al., 2014). 
Uma nova paisagem urbana foi se delineando e ganhando visibilidade à medida que, na dinâmica do cotidiano, os usos de tais espaços por diferentes sujeitos dotaram-na de identidade, conferida pelo seu potencial de um referencial ligado às atividades culturais e de localização. O prédio da Reitoria tornou-se um dos mais significativos referenciais de orientação espacial na cidade de Fortaleza. Impregnado de significações e memória, ganhou o contorno de "uma imagem pública".

Para Renato Mesquita Rodolfo (2015, p. 77), “[...] a dinâmica de morar, de conviver e de circular nas vias do bairro passava a ser atravessada pela dinâmica universitária do ensino, das vivências estudantis e dos eventos acadêmicos". Na dissertação intitulada "A Universidade (Federal) do Ceará entre o Benfica e a Gentilândia: espaços, lugares e memórias - 1956-1967” (2015), desenvolvida no percurso deste inventário, foram examinadas as dinâmicas e sensibilidades que passaram a operar a nova configuração do bairro e sua produção de memórias, a partir da chegada da Universidade.

Se os referenciais de um bairro universitário e de um bairro boêmio emergem imbricados nas relações dos moradores e não moradores com o bairro e com a Universidade, também a política é outro referencial ligado ao Benfica que, igualmente, o qualifica como um bairro político. A própria criação da Universidade é fruto do desejo e acordos entre as elites intelectuais e políticas do Estado. Desde que a Universidade se instalou no Benfica, o bairro passou a fazer parte do roteiro dos políticos que estavam de passagem por Fortaleza ou de candidatos em época de eleições.

Ao longo dos anos, o bairro assistiu o domínio da política se constituir em um referencial de identidade capaz de moldar uma "paisagem efêmera" ao transformar a Avenida da Universidade no "corredor da política". A Avenida, que concentra um conjunto expressivo de equipamentos da UFC (Reitoria, Radio Universitária, Centro de Treinamento e Desenvolvimento (CETREDE), Museu de Arte da UFC (MAUC), Centro de Humanidades - CH I e II, Casa do Estudante, Casa Amarela, Restaurante Universitário, Faculdade de Economia, Administração, Atuária, Contabilidade (FEAC), Teatro Universitário) e outros (Sindicato das Universidades Federais do Estado do Ceará (ADUFC), Biblioteca Dolor Barreira, Teatro Chico Anísio, etc.), se viu tomada por sedes de partido e por uma "invasão" dos comitês dos postulantes aos cargos do executivo e legislativo em período eleitoral. As comemorações dos resultados das eleições consagraram definitivamente a Avenida como "corredor da política", tomando o lugar de praças tradicionais como a praça do Ferreira.

No período das campanhas eleitorais, o bairro ganha uma dinâmica diferenciada. Durante esses meses, uma coreografia é ensaiada por corpos enfileirados com camisetas e bonés, flamulando bandeiras nos principais cruzamentos da 
Avenida da Universidade (Avenida Treze de Maio e Domingos Olímpio). Todas essas atividades mobilizam sujeitos das mais diversas localidades da cidade para o Benfica. Nesse processo, as pessoas experimentam um convívio maior no bairro, na Avenida e, consequentemente, desenvolvem novas percepções e atitudes para com o espaço tornando-o comum não somente nesse período. Sobre essa relação da política no Benfica, o relato de Laurence é categórico:

Um fato histórico que ocorreu no Benfica... hã... tem os movimentos, por exemplo, o Fora Collor, boa parte dos movimentos começaram exatamente pelo CEFET (atual Instituto Federal de Educação Ciência e Tecnologia do Ceará - IFCE), na universidade, nas escolas que começaram a concentração, ali, na Praça da Gentilândia, né. (Entrevista realizada em 19/09/2012).

Percebe-se que a política no Benfica é um elemento que implica no despertar de uma sensibilidade pretérita, uma vez que mobiliza a memória e contribui para construir a identidade do bairro associada a esse referencial.

A Praça da Gentilândia (nome oficial Abolicionista Amaral) figura como um dos mais importantes espaços comuns de referência cultural para o Benfica e para a cidade de Fortaleza. Sua condição de lugar foi construída por distintos sujeitos e usos que informam dos sentidos diversos atribuídos à praça dependendo da hora e do dia da semana. Em meio às reformas e processos de modernização da cidade, múltiplas identidades foram se constituindo forjadas no tempo e no cotidiano que fizeram da praça um lugar de memória. (NORA, 1993). Espaço de lazer e de sociabilidade, de movimentos políticos e sociais, de trabalho e rendimento econômico, de experiências gustativas e sonoras... Saberes e fazeres repertoriam práticas urbanas que traduzem as sensibilidades e subjetividades que ali giram em torno da alimentação conformando uma memória olfativa e gustativa. Ganham destaque em virtude da feira livre e das barracas de "comidas típicas" e outras que se instalam na praça.

Situada no coração do Benfica, entre o IFCE, o Estádio Presidente Vargas (PV), a Casa do Estudante, a UFC e o shopping Benfica (quadrilátero das ruas Santo Antônio, Paulino Nogueira, Marechal Deodoro e Interna), a praça recebe, além de seus moradores tradicionais e o público universitário, fanáticos torcedores que se encontram semanalmente para dali se dirigirem para o PV.

Dona Erismar e Seu Francisco são praticantes do espaço. Há mais de quinze anos montam a barraca de legumes, na feira da Gentilândia, apenas nos fins de semana. No relato de ambos, é a experiência do ofício de feirante que 
confere o sentido de lugar ao Benfica. A percepção do lugar e a manifestação de afeto de Dona Erismar pelo Benfica são mediadas pela realidade concreta do ofício que apura os sentidos:

É muito ventilado, a gente fica lá à vontade. Eu gosto muito lá do Benfica. Quinze anos que eu trabalho lá: num troco a minha feira de lá por outra feira nenhuma. A minha clientela é muito boa. São aposentados. E eu adoro muito a minha venda. Eu gosto muito da minha feira por causa disso. É pertinho de casa. Não gasta muita gasolina pra sábado e domingo... Quer dizer, eu adoro a minha feira. A gente pode ficar naquela sombra à vontade. (Entrevista realizada em 7/08/2012).

O relato acima é mais uma amostra das temporalidades subjetivas que conformam o espaço do Benfica. Ele "atravessa e organiza os lugares". (CERTEAU, 1994, p. 199). Nele, os sentidos do lugar nos mostram que é preciso ir além da materialidade objetivada da cidade, qual seja: a "Praça da Gentilândia" e sua feira. Aqui, as práticas sociais e o consumo diário do espaço nos ensinam que é possível ver além daquilo que é dado a ver, ou seja, conhecer um lugar é ir ao encontro do sentimento de topofilia desenvolvido. No relato de Dona Erismar, a sinestesia a acompanha no exercício do ofício de feirante com o ambiente da praça: frente à sensação de calor e o sol implacável, a sombra e o vento; frente à dureza da faina, a companhia da clientela.

Os anos de convivência com o espaço da praça e com seus clientes foram diluindo as fronteiras entre o público e o privado e fazendo do bairro do Benfica um espaço de territórios interpenetráveis, lugar familiar. Ganha um sentido de lar em que os colegas de ofício e os clientes formam uma grande família, como diz Seu Francisco:

Quer dizer, a Marlene, nós e aquela que vende polpa é quase uma familia só. Nós ajuda lá, eles ajuda nós aqui. Essa é a grande coisa que a gente tem que dar de valor ao Benfica é isso aí. As nossa amizade que construímos ali, graças a Deus! (Entrevista realizada em 7/08/2012).

Já a praça é como o quintal da casa onde se pode ficar à vontade naquela sombra ventilada e receber os amigos. A sensação do aprazível e do aconchego, assim como a amizade e a solidariedade, leva à noção dinâmica de bairro desenvolvida por Certeau (1995). Na tensão entre o dentro e o fora, "o engaja- 
mento do corpo do usuário no espaço público" necessita de uma "progressiva aprendizagem" para aí efetivar uma apropriação. Diante de tal constatação, "[...] o bairro pode ser considerado como a privatização progressiva do espaço público". (CERTEAU, 1994, p. 43, passim).

A Praça José Gentil, também conhecida por "Praça da Gentilândia" (com a frente para a Av. 13 de Maio, paralelas as ruas Waldery Uchôa e João Gentil e fundos Paulino Nogueira) é palco de blocos de carnaval e dos Festivais de Cultura da UFC, ponto de encontro e de luta pela diversidade sexual. Estas praças, entrelaçadas aos bares do Benfica, que ficam no seu entorno - o Bar do Seu Chaguinha (inaugurado em 1956 e fechado em 2015), o Bar do Seu Assis, o Bar Cantinho Acadêmico, o Bar do Pitombeira, entre outros -, fazem do Benfica um local praticado, representam um espaço animado pelos movimentos que ali se desdobram revelando testemunhos temporais e sensoriais de grupos sociais que fazem uso desses lugares.

Como se pode observar, o inventário permitiu identificar, sobretudo pelas narrativas orais, diferentes temporalidades subjetivas que configuram uma cartografia dos sentidos do Benfica. Acionados pela história oral, tais relatos se constituíram em registros de acesso tanto à dimensão tangível do espaço, dada a ver pela sua materialidade, quanto à dimensão do intangível, aquela associada ao universo do simbólico e da percepção, dos valores e do ponto de vista. Permanências e mudanças sentidas nas práticas diárias dos entrevistados foram convergindo para o entendimento da memória como "um processo ativo de criação de significações". (PORTELLI, 1997, p. 33), do qual as narrativas construídas tenderam a se apresentar sempre acumuladas de referenciais dos processos de transformação do urbano.

Todo esse processo requer, como se viu, uma educação dos sentidos, se quisermos recuperar as práticas sociais que nos ajudem a compreender os significados atribuídos, pelos moradores da cidade, ao seu patrimônio cultural. Contribuir para desnaturalizar os processos de patrimonialização do passado da cidade, atentando para as singularidades que envolvem a constituição de seu respectivo acervo, é o papel da universidade e seu desafio.

\section{REFERÊNCIAS}

ABREU, Marta. Cultura imaterial e patrimônio histórico nacional. In: Cultura política e leituras do passado: historiografia e ensino de História. Rio de Janeiro: Civilização Brasileira, 2007. 
ALBERTI, Verena. Manual de História Oral. Rio de Janeiro: FGV, 2005.

ASSMAN, Aleida. Espaços da recordação: formas e transformações da memória cultural. Campinas: Editora da Unicamp, 2011.

AZEVEDO, Miguel Angelo de (Nirez). Fortaleza, ontem e hoje. Fortaleza: PMF/ FUNCET, 1991.

BARROSO, Francisco de Andrade. O Benfica de ontem e de hoje: memória de uma época, descrição do bairro, ruas, cãs, equipamentos, instituições, famílias, pessoas, costumes, tradições, folclores. Estado atual. Fortaleza: edição do autor, 2004.

BENJAMIN, Walter. Rua de mão única. In: Obras escolhidas II. São Paulo: Brasiliense, 1993.

BRECIANI, Maria Stella. Memória, cidade e sensibilidade urbana. In: BERNARDES, M. E.; GALZERANI, M. C. B. (Org.). Memória, cidade e sensibilidade urbana. Campinas: Centro de Memória da Unicamp, 2014.

CANDAU, Joel. Memória e identidade. São Paulo: Contexto, 2011.

CANEVACCI, Massimo. A cidade polifônica: ensaio sobre a antropologia da comunicação urbana. 2. ed. São Paulo: Studio Nobel, 1997.

CERTEAU, Michel. A invenção do cotidiano: 1. Artes de fazer. Petrópolis: Vozes, 1994.

CHUVA, Marcia. A História como instrumento na identificação dos bens culturais. In: Inventários de identificação: um panorama da experiência brasileira. Rio de Janeiro: IPHAN/Minc, 1998.

FENELON, Déa R. São Paulo: Patrimônio histórico-cultural e referências culturais. Revista Projeto História: Espaço e Cultura, São Paulo: EUC, n. 18, 1999.

FONSECA, Maria Cecília Londres. A noção de referência cultural nos trabalhos de inventário. In: MOTA, L.; SIVA, M. B. R. (Org.). Inventários de identificação: um panorama da experiência brasileira. Rio de Janeiro: IPHAN/COPEDOC, 2008.

FUAN, Yi Fu Tuan. Topofilia: um estudo da percepção, atitudes e valores do meio ambiente. Londrina: Eduel, 2012.

GUIMARÃES, Manoel Luís Salgado. História, Memória e Patrimônio. Revista do Patrimônio Histórico e Artístico Nacional: História e Patrimônio, Brasília: IPHAN, n. 34, 2011.

HALBWACHS, Maurice. A memória coletiva. São Paulo: Vértice, 1990.

HARTOG, François. Tempo e patrimônio. Varia Historia, Belo Horizonte, v. 22, n. 36, 2006.

HUYSSEN, Andreas. Seduzidos pela memória: arquitetura, monumentos, mídia. Rio de Janeiro: Aeroplano, 2000. 
JEUDY, Henri-Pierre. Espelho das cidades. Rio de Janeiro: Casa da Palavra, 2005.

JUCÁ, Clovis; GONÇALVES, A.; BRASIL, A. C. Arquitetura moderna campus do Benfica: Universidade Federal do Ceará. Fortaleza: Edições UFC, 2014.

LE GOFF, Jacques. Por amor às cidades: conversações com Jean Lebrun. São Paulo: UNESP, 1988.

MENESES, Ulpiano T. Bezerra. O museu na cidade X a cidade no museu: para uma abordagem histórica dos museus de cidade. Revista Brasileira de História: Cultura \& Cidades, São Paulo: ANPUH, n. 8/9, 1985.

NOGUEIRA, Antonio Gilberto R. Inventário e patrimônio cultural no Brasil. História, São Paulo, v. 26, n. 2, p. 257-268, 2007.

NOGUEIRA, Antonio Gilberto R. O campo do patrimônio cultural e a história: itinerários conceituais e práticas de preservação. Revista Antiteses: História e antropologias do patrimônio, Londrina: UEL, v. 7, n. 14, 2014.

NOGUEIRA, Antonio Gilberto R. et al. Benfica em três tempos: patrimônio, inventário e memória local. In: CHUVA, M.; NOGUEIRA, A. G. R. (Org.). Patrimônio Cultural: políticas e perspectivas de preservação no Brasil. Rio de Janeiro: Mauad X/Faperj, 2012.

NORA, Pierre. Entre memória e história: a problemática dos lugares. Projeto História: História \& Cultura, São Paulo: PUC, n. 10,1993.

PEREIRA, Ilaina Damasceno. Lugares no bairro: uma etnografia no Benfica. Dissertação (Mestrado em Geografia) - Universidade Federal do Ceará, Fortaleza, 2008.

PESAVENTO, Sandra Jatahy. História \& História Cultural. Belo Horizonte: Autêntica, 2004.

PESAVENTO, Sandra Jatahy. Cidade, Espaço e Tempo: reflexões sobre a memória e o patrimônio urbano. Cadernos do LEPAAQ: Textos de Antropologia, Arqueologia e Patrimônio, Pelotas, RS: Editora da UFPEL, v. 11, n. 4, ago/dez 2005.

PESSOA, Fernando. Alberto Caeiro, in "O Guardador de Rebanhos - Poema XXIV”. p. 44-45. Disponível em: <http://cdn.luso-livros.net/wp-content/uploads/2013/06/Poemas-de-Alberto-Caeiro.pdf>. Acesso em: 24 set. 2015.

PORTELLI, Alessandro. O que faz a história oral diferente. Projeto História: Cultura e Representação, São Paulo: EDUC, n. 14, 1997.

RIBEIRO, Rafael Winter. Paisagem cultural e patrimônio. Rio de Janeiro: IPHAN/ COPEDOC, 2007.

RODOLFO, Renato Mesquita. A Universidade (Federal) do Ceará entre o Benfica e a Gentilândia: espaços, lugares e memórias (1956-1967). Dissertação (Mestrado em História) - Universidade Federal do Paraná, Fortaleza, 2015. 
SANT'ANNA, Márcia. A face imaterial do patrimônio cultural: os novos instrumentos de reconhecimento e valorização. In: Memória e Patrimônio: Ensaios Contemporâneos. RJ: DP\&A, 2003.

SANTOS, Milton. Metamorfoses do espaço habitado. 3. ed. São Paulo: Hucitec, 1994.

SARLO, Beatriz. Tempo passado: cultura da memória e guinada subjetiva. São Paulo:

Cia das Letras/UFMG, 2007.

\section{FONTES ORAIS}

BISOL, Laurence Kroeff, 19 set. 2012. Entrevista.

COSTA, Clarice. 14 jan. 2015. Entrevista.

FERREIRA, Erismar. 07 ago. 2012. Entrevista.

FERREIRA, Francisco. 07 ago. 2012. Entrevista.

MARTINS, Francisco de Assis. 22 ago. 2012. Entrevista.

Texto recebido em 11 de outubro de 2015 .

Texto aprovado em 11 de outubro de 2015. 
